\title{
STEP FREQUENCY RADAR EXPERIMENTS ON THE ANTARCTIC SEA ICE
}

\author{
Seiho Uratsuka ${ }^{1}$, Fumihiko Nishio ${ }^{2}$, Ken'ichi OKamoto ${ }^{1}$, \\ Hitoshi MINENO ${ }^{3}$ and Shinji MAE ${ }^{4}$ \\ ${ }^{1}$ Communications Research Laboratory, Ministry of Posts and \\ Telecommunications, 2-1, Nukui-kitamachi 4-chome, \\ Koganei 184 \\ ${ }^{2}$ National Institute of Polar Research, 9-10, Kaga \\ 1-chome, Itabashi-ku, Tokyo 173 \\ ${ }^{3}$ Kimitsu Satellite Control Center, Telecommunication Satellite \\ Corporation of Japan, 1743-5, Sasa, Kimitsu 292-05 \\ ${ }^{4}$ Department of Applied Physics, Faculty of Engineering, Hokkaido \\ University, Kita-13, Nishi-8, Kita-ku, Sapporo 060
}

\begin{abstract}
Step frequency radar experiments have been carried out on sea ice near Syowa Station as part of the 27th Japanese Antarctic Research Expedition to develop an airborne sensor for measuring vertical sea ice structures. Step frequency radar has characteristics of high resolution and low frequency (UHF band), which is an advantage in measuring sea ice. The experiments are the first application of this radar for measuring sea ice thickness. The radar transmits 32 different frequencies in a stepwise fashion between 300 and $796 \mathrm{MHz}$ and measures the amplitude and phase of reflected waves at each frequency. The discrete Fourier transform of the 32 complex values of signals indicates the distance of vertical sea ice structures. The range resolution is about $15 \mathrm{~cm}$ in sea ice. The experimental results showed that the radar system could successfully measure vertical sea ice structures: (1) The distance between the surface and the snow/ice interface or between the surface and the sea ice bottom deduced by this method coincided with direct measurements in sample holes. (2) Snow depth was measured very clearly by the radar system.
\end{abstract}

\section{Introduction}

The developments of the technique to measure the sea ice thickness remotely is in demand for effective navigation in the icebound sea and for sea ice sciences, but it is difficult to realize because of large attenuation of microwaves which is useful to design high resolution pulse radar. Some types of radars have been applied to measurements of lake ice thickness, for example, the impulse radar (CAMPBELL and ORANGE, 1974), the HISS radar (IIzUKA et al., 1976), and the step frequency radar. The principle of the step frequency radar had been proposed by IIzUKA (1978), IIzUKA et al. (1984) and Wu (1978) in order to survey the targets in the soil or the sea ice thickness.

In the step frequency radar, the distance to a target is measured by observing the change in the phase of received signal with respect to a change in the frequency of the transmitted signals. For a given change $\Delta \beta$ in wave number (or in frequency), the 
change in the phase of the reflected signal from a target at a distance $d$ become $2 \Delta \beta d$ and hence is proportional to the distance $d$. We developed a step frequency radar at UHF band to measure sea ice thickness aiming at the practical airborne sensor, and the preliminary tests of our system were carried out in the anechoic chamber before the antarctic experiments to confirm the basic principle, and resulted to detect iron pipes or aluminum plates in the sand (Окамото et al., 1986).

Experiments on this system had been carried out on the sea ice near Syowa Station antarctica during the 27th Japanese Antarctic Reasearch Expedition. This is the first case of experiments to measure sea ice thickness by the principle of a step frequency radar system.

\section{Summary of the Experimental Step Frequency Radar System}

As the details of our system had been reported in Окамото et al. (1986), we will review major characteristics of this system. Major characteristics of this step frequency radar are shown in Table 1, and a block diagram is shown in Fig. 1. The radar transmits 32 different frequencies in a stepwise fashion between 300 and $796 \mathrm{MHz}$ using the right-hand circular polarized cavity-backed-spiral antenna. The coherent receiver picks up amplitudes and phases of reflected waves of every frequency using a left-hand circular polarized antenna. We can obtain the distance to the targest through the discrete Fourier transform of these complex signals. The range resolution of our system is about $30 \mathrm{~cm}$ in air and is expected to be about $15 \mathrm{~cm}$ in sea ice and about $20 \mathrm{~cm}$ in snow.

\section{Experiments on Sea Ice}

The objectives of the experiments are (1) confirmation of the validity of the step frequency radar to measure vertical sea ice structure and (2) checking problems to design an optimum airborne system. To accomplish the former objective, experiments

Table 1. Parameters of the experimental step frequency radar.

\begin{tabular}{ll}
\hline Transmitting frequency & $300-796 \mathrm{MHz}$ \\
& $(32$ frequencies with the step of $16 \mathrm{MHz})$ \\
Transmitting power & Maximum $400 \mathrm{~mW}$ \\
Range resolution & $0.293 \mathrm{~m}$ in the air \\
Maximum observable distance & $9.08 \mathrm{~m}$ in the air \\
Antenna type & Cavity-backed spiral antenna (Right-handed circular \\
& polarized and left-handed circular polarized antenna) \\
Antenna gain & More than $8.3 \mathrm{~dB}$ \\
Antenna beam width & About 70 degrees \\
Isolation between antennas & More than $40 \mathrm{~dB}$ (when the distance between centers \\
& of antennas are $80 \mathrm{~cm}$ ) \\
Antenna VSWR & Less than 1.5 \\
Antenna diameter & About $45 \mathrm{~cm}$ \\
Antenna weight & About $5.3 \mathrm{~kg}$ \\
Time required for one & About $30 \mathrm{~s}$ \\
measurement sequence &
\end{tabular}




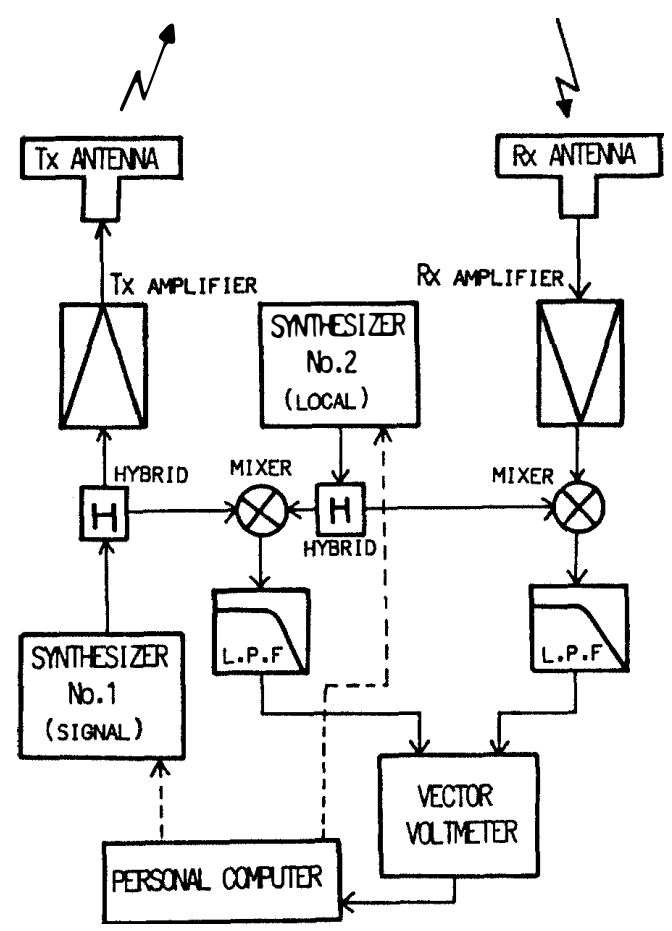

Fig. 1. Block diagram of the experimental step frequency radar.

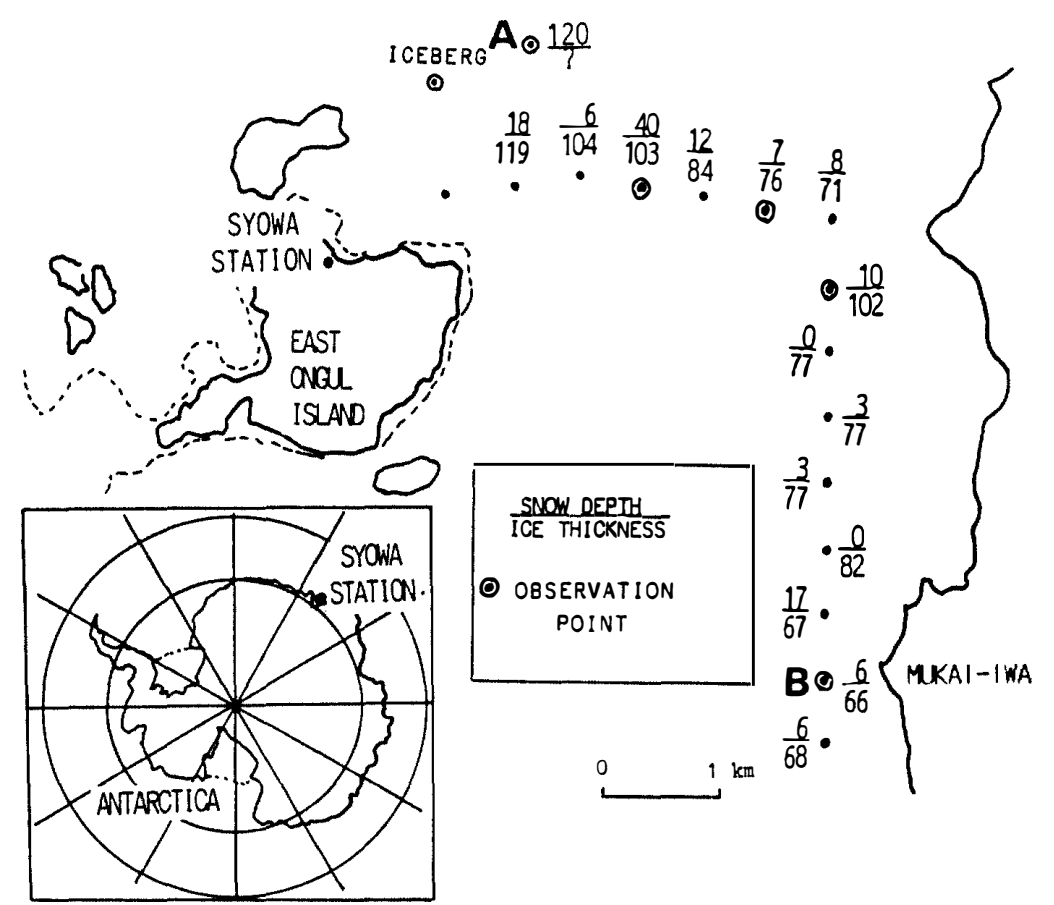

Fig. 2. Location of experimental observation points.

were conducted at six observation points on sea ice in different conditions, for example on first-year ice, multi-year ice, and thick snow pack on sea ice. The points were about 2 to $5 \mathrm{~km}$ apart from Syowa Station. The snow depth and sea ice thickness around the observation points are shown in Fig. 2. At the observation points, drill 
hole core samples were taken to measure the vertical structures of salinity and density, and to measure the sea ice thickness through the core hole. The sea ice thickness at the observation points was 60 to $120 \mathrm{~cm}$ and the snow depth was 0 to $120 \mathrm{~cm}$ as shown in Fig. 2.

At every observation point, all equipment except antennas were set up in an oversnow-vehicle on sea ice. The antennas were put on legs which were one meter tall and directed downward. The radar measured sea ice at five different positions one meter apart from each other at every observation point. The phase and gain of the radar system were calibrated using an aluminum plate below the antennas.

\section{Results}

The diagrams of distance to reflected amplitude are calculated by Fast Fourier Transform processing of the complex values of calibrated signals. We chose two examples of results which represent characteristics of all the results of the experiments and which have less instrumental error since we often had instrument trouble in the experiments.

One measurement of sea ice on which there was thick snow pack is shown in Fig. 3. The location is indicated by A in Fig. 2. The 0-th spectral number corresponds to the distance between the antenna and the calibration plane (on the sea ice surface). As the propagation speed in snow in this case was inferred to be 0.66 times the propagation speed in air by the density of a snow sample, the distance $d_{n}$ from the calibration plane to the target is proportional to the spectral number $n$ and is obtained from the expression $d_{n}=20 \times n(\mathrm{~cm})$ in the snow pack. In Fig. 3 there are two sharp peaks. The first peak indicates the snow surface and the second peak indicates the snow/ice interface. Thus, it is inferred that the snow depth was about $120 \pm 20 \mathrm{~cm}$. As the actual depth of the snow pack was $120 \mathrm{~cm}$ at this point, the step frequency radar measurement coincides with the real snow depth.

Figure 4 shows five processed results on the first year sea ice. The location is indicated by B in Fig. 2. The five results, shown on a common abscissa, were obtained by shifting antennas one meter apart from each other. In every result except those indicating 0 -th, the peaks seem not clear. However, we can find isolated peaks at the fifth spectral number of all results. The propagation speed in sea ice was calculated to be about $50 \%$ of the speed in air from the salinity and density of the sample and mean temperature at the observation point using the model of VANT et al. (1978). Therefore, the fifth spectral number corresponds to about $75 \pm 15 \mathrm{~cm}$ in the sea ice. This coincides with the direct measurement $(66 \mathrm{~cm})$ through the drill holes.

\section{Concluding Remarks}

It was confirmed that the step frequency radar system is effective in measuring sea ice vertical structure. The distance between snow surface and snow/ice interface or between snow surface and the bottom of the sea ice deduced by this method agreed with the direct measurements through the drill holes. Even though the snow depth was detected very clearly, it was not easy to recognize the echo from the bottom of 


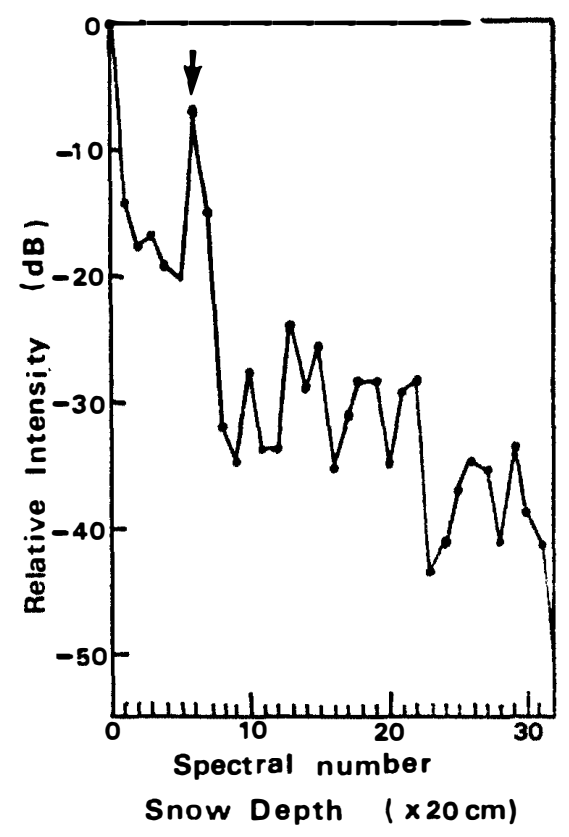

Fig. 3. One example of a step frequency radar measurement on thick snow over sea ice.

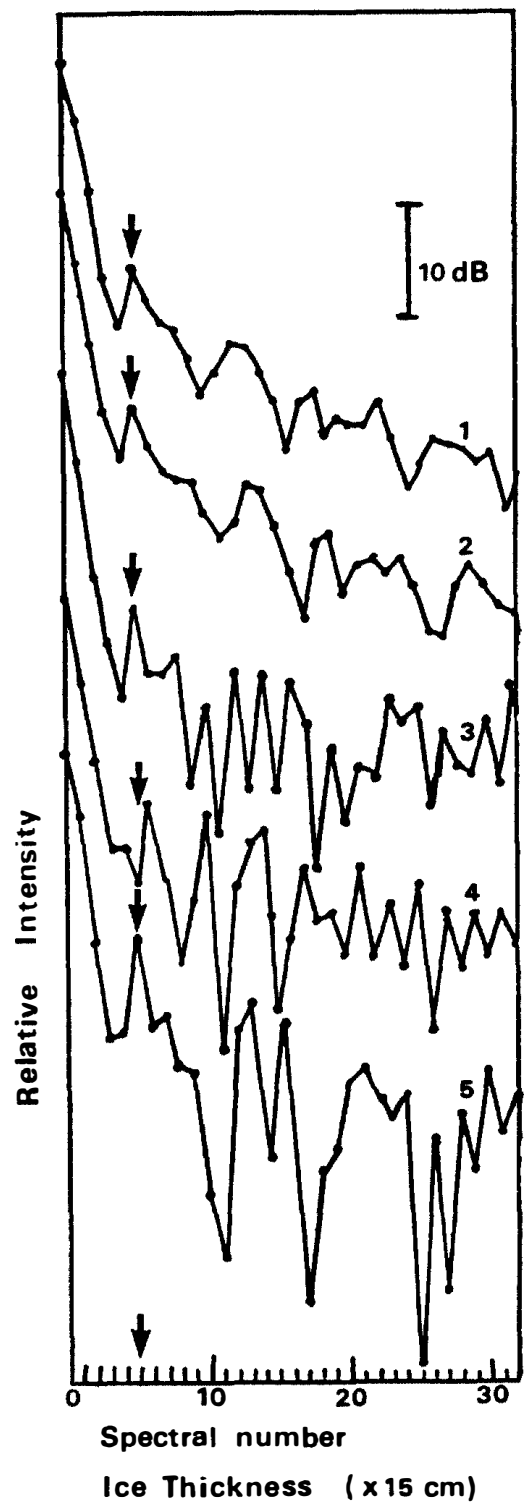

Fig. 4. Results of the step frequency radar measurement on sea ice.

the sea ice because the difference between relevant echo peak and noise levels of large spectral numbers is not much. The reason for the difficulty in recognizing bottom peaks may be as follows:

(1) Reflected power from the bottom of the sea ice is weaker than that from the surface

In this radar system, if the difference in signal strength between the bottom of the sea ice and the surface is beyond dynamic range, the echo strength from the bottom of the sea ice will be masked. It was discovered that the difference in spectral power between the sea ice surface and the bottom of the sea ice was about 15 to $20 \mathrm{~dB}$. The dynamic range of the original system was sufficient $(40 \mathrm{~dB})$. However, the narrow dynamic range may have occurred because of instrument malfunction.

(2) The wide beam-width effect of the antennas and scattering on the surface of 
sea ice

Although the area covered simultaneously by transmitting and receiving antenna beams is adequate, different paths between the transmitting and receiving antennas cause ambiguity in determining spectral peaks when the surface is rough because of the antennas' wide beam-width.

(3) The problem in the phase calibration method

The calibration method is based on the plane wave theory, which assumes that waves with only a small incidence angle reflect. If the antenna receives strong reflected waves with a large incidence angle, this calibration method will not provide the correct data in the system.

(4) The numerical problem of finite Fourier transform

One method of avoiding the problem is the so called window method. However, transformations using various windows did not result in getting clear peaks.

Finally, when we design a operational airborne system, the prober beam pattern of the airborne antenna is most important. It is also important to find a better method to calibrate the phase and gain of the radar system. Further study of the above problems will be conducted.

\section{Acknowledgments}

We would like to express our sincere gratitude to Prof. Yasuhiko NaITo who is leader of the wintering team of the 27th Japanese Antarctic Research Expedition (JARE-27). We are also grateful to all members of the JARE-27 team for logistic and technical support to this field experiment.

\section{References}

Camprell, K. J. and Orange, A.S. (1974): A continuous profiles of sea ice and freshwater ice thickness by impulse radar. Polar Rec., 17, 31-41.

IIzukA, K. (1978): Unsolicited Proposal for Developing a Step Frequency Radar for Measuring Thickness of Sea Ice. Tronto, University of Toronto, $14 \mathrm{p}$.

Iizuka, K., Ogura, H., Yen, J. L., Nguyen, V. K. and Weedmark, J. R. (1976): A hologram matrix radar. Proc. IEEE, 64, 1493-1504.

Iizuka, K., Freundorfer, A. P., Wu, K. H., Mori, H., Ogura, H. and Nguyen, V. K. (1984): Step-frequency radar. J. Appl. Phys., 56, 2572-2583.

Oxamoto, K., Mineno, H., Uratsuka, S., Inomata, H. and Nishio, F. (1986): Step frequency radar for the measurement of sea ice thickness. Mem. Natl Inst. Polar Res., Spec. Issue, 45, 56-65.

VANT, M. R., Ramseier, R. O. and Makios, V. (1978): The complex-dielectric constant of sea ice at frequencies in the range 0.1-40 GHz. J. Appl. Phys., 49, 1264-1280.

Wu, K. H. (1978): Step Frequency Radar; A Thesis for the Degree of Master of Applied Science. Tronto, Univeristy of Toronto, $121 \mathrm{p}$.

(Received March 3, 1988; Revised manuscript received December 16, 1988) 